\title{
Virgen de la Misericordia, San Jerónimo y San Miguel: el origen del corporativismo sedero en la Valencia bajomedieval (1465-1518)
}

\author{
Virgin of Mercy, Saint Jerome and Saint Michael: The Origins of the \\ Silk Guilds of Late Medieval Valencia (1465-1518)
}

JuAn Martínez Vinat

vinat2@uv.es

Universitat de València

\begin{abstract}
Resumen: El presente estudio indaga sobre el origen del asociacionismo sedero valenciano a través de las tres principales corporaciones fundadas en Valencia a finales de la Edad Media: la cofradía de la Misericordia de veleros de seda, la cofradía de San Jerónimo del Art de Velluters y la cofradía de tintoreros de seda de San Miguel. El análisis de sus ordenanzas confraternales y gremiales, contrastado con otras fuentes documentales de tipo contable (Llibres de Dates e Rebudes), nos permiten conocer la realidad, funcionamiento y desarrollo de tres entidades que protagonizaron el arranque de la sedería valenciana, tanto desde la perspectiva laboral como desde la óptica benéficoasistencial, ambas inseparables en el periodo que nos ocupa.
\end{abstract}

Palabras clave: seda, corporativismo sedero, Valencia, cofradías, gremios

\begin{abstract}
This essay enquires into the origins of the Valencian silk coorporativism though the three main guilds of late medieval Valencia: the confraternity of The Mercy of silk weavers, the confraternity of Saint Jerome of the Art de Velluters, and the confraternity of Saint Michaels' silk dyers. The analysis of their rules will be contrasted with account records (Llibres de Dates e Rebudes). This will allow finding out the functioning and development of these three entities, which proved essential for the trigger of Valencian silk industry. Such an analysis will be conducted both from a work and relief-based view since these ar inseparable in this period.
\end{abstract}

Keywords: silk, silk coorporativism, Valencia, confraternities, guilds 
Juan Martínez Vinat. Virgen de la Misericordia, San Jerónimo y San Miguel: el origen del corporativismo sedero en la Valencia bajomedieval (1465-1518)

\section{Introducción.}

El origen y desarrollo de las corporaciones de oficio vinculadas a la seda en Valencia está íntimamente relacionado con el impulso económico, manufacturero y comercial que experimentó la capital del reino durante el periodo bajomedieval, el cual favoreció a su vez el auge de corporaciones de menestrales, autóctonos y foráneos, que asumieron competencias de índole profesional, religioso y asistencial con el fin de proteger a sus agremiados, asegurar la calidad de sus productos y velar por el cumplimiento de sus ordenanzas y privilegios, garantizando así la proyección de su oficio. En esta etapa brillante para el asociacionismo artesanal valenciano, los profesionales de la seda no constituyeron una excepción. Las corporaciones de tejedores de seda, velluters y tintoreros de Valencia, creadas en la segunda mitad del siglo XV, irrumpieron bajo la forma de cofradías profesionales acogiéndose al patronazgo de la Virgen de la Misericordia, San Jerónimo y San Miguel, respectivamente.

El nacimiento del corporativismo sedero, sin embargo, no debe confundirse con la aparición de la actividad sedera en Valencia. Su origen se remonta más bien al periodo de dominación andalusí. De hecho, tras la conquista de Persia en el siglo VII, los musulmanes heredaron el control de la ruta de la seda, difundiendo los saberes técnicos originarios de oriente por todo el Mediterráneo occidental. Al-Andalus sería la primera región del continente europeo donde se criaron gusanos de seda de forma masiva (sericicultura), bien documentada a partir del siglo X, favoreciendo el desarrollo de sus manufacturas. Esta tradición musulmana no desaparecería tras la conquista cristiana del siglo XIII, al contrario, fue conservada de padres a hijos por artesanos mudéjares y judeo-conversos manteniendo su difusión y una oferta clara de productos hasta época moderna (Navarro 2002:302 у 2004:23).

Desde la llegada de Jaime I la organización del sector se vería potenciada con la existencia de talleres artesanales dispersos ubicados en torno a los núcleos urbanos de Xàtiva y Valencia. En este contexto, mercaderes y menestrales mudéjares, judíos y conversos ejercieron un papel activo en la redistribución comercial de la seda granadina desde el siglo XIII. En la centuria siguiente aparecen en Valencia las primeras reglamentaciones que evidencian la pervivencia de la vieja tradición musulmana en algunos oficios emergentes de época cristiana. Precisamente, en 1316, unas ordenanzas municipales aluden al oficio de fabricantes de correas de seda y filadiz, instando a sus menestrales a utilizar fibra pura en su elaboración, evitando las mezclas perjudiciales para la calidad del producto. Este grupo profesional de corretgers y seders, que aparece desfilando en segundo lugar en la recepción de los duques de Gerona de 1373, constituiría el «embrión de la futura sedería valenciana, cuya oferta fundamental era obras finas de seda, pasamanería y mezclas de algodón» (Navarro y Martínez 2016:25).

La existencia de profesionales del sector sedero en Valencia estaría atestiguada también entre finales del siglo XIV y la primera mitad del siglo XV con una nómina de más de cincuenta sederos y tejedores judeoconversos que trabajaban en el antiguo zoco judío de la ciudad, mientras que los 
Juan Martínez Vinat. Virgen de la Misericordia, San Jerónimo y San Miguel: el origen del corporativismo sedero en la Valencia bajomedieval (1465-1518)

residentes de la morería se dedicaban al comercio sedero con el reino de Granada, donde se ha podido localizar una importante colonia de mercaderes cristianos valencianos que establecieron un contrato de la seda con el sultán Yusuf III en 1417 para controlar la producción textil del reino nazarí (Navarro 2002:297).

El primer grupo, el de los judeo-conversos, configuraría en la segunda mitad del siglo XV el germen de la primera corporación de artesanos sederos reconocida por las autoridades en Valencia, los tejedores de velos de seda. Mientras que la aparición del gremio de terciopeleros o velluters en los años 70 del siglo XV estaría más bien vinculada a la llegada de inmigrantes italianos, fundamentalmente genoveses, que implantaron en la capital del reino una técnica bien conocida en sus lugares de origen. Sin embargo, las corporaciones de tejedores y velluteros no fueron las únicas vinculadas al sector que formaron cofradía profesional, aunque sí las primeras con una estructura reconocida. A finales del siglo XV, concretamente en septiembre de 1497, los sederos y tintoreros de seda de Valencia solicitaban al Consell general autorización para crear una cofradía bajo el patronazgo del arcángel San Miguel. Sin embargo, los capítulos no serían aprobados hasta 1506, siendo ratificados poco después por el monarca Fernando el Católico. ${ }^{1}$ No sería la última. El 3 de diciembre de 1516 los jurados de Valencia aprobaban las ordenanzas fundacionales del gremio de pasamaneros, instituido bajo la advocación de la Virgen del Socorro. ${ }^{2}$ Finalmente, el oficio de fabricantes de parches y listas de seda se independizaba de los tejedores y pasamaneros como oficio corporado recibiendo sus propias ordenanzas en el año 1519, en vísperas de las Germanías (Navarro 1996:34 y 2004:25). Todo ello evidencia el grado de complejidad y especialización que adquirió una industria en auge en Valencia, la de la seda, en el tránsito hacia la Modernidad, manifestada a través de la multiplicación de corporaciones vinculadas al sector. En el presente estudio nos ceñimos a las tres primeras: la cofradía de tejedores de velos de seda de la Virgen de la Misericordia, la cofradía de San Jerónimo del Art de velluters y la cofradía de tintoreros de seda de San Miguel.

\section{Velers $i$ seders. La cofradía de la Virgen de la Misericordia (1465-1518).}

El oficio de tejedores de velos de seda de Valencia instituido bajo la advocación de la Virgen de la Misericordia sería el primero en erigirse como cuerpo orgánico de profesionales. Antes del reconocimiento institucional formalizado en 1465, los veleros valencianos se reunían en el convento de los Predicadores para celebrar su festividad patronal con misas, aniversarios y limosnas al menos desde 1460 (Teixidor 1755:120 y Navarro 1992:43). Formado en su mayoría por menestrales de origen judeo-converso, el colectivo artesanal asumió competencias muy pronto gracias a las ordenanzas concedidas por la autoridad municipal o real entre 1465 y 1499, las cuales conjugaban fines religioso-benéficos con la normativización del ejercicio profesional, especializado en la

1 Archivo del Reino de Valencia (ARV). Real Cancillería, reg. 312, fols. 266r-273r.

2 Archivo Municipal de Valencia (AMV). Manual de Consells (MC). A-57, fols. 181r-189v.

SCRIPTA, Revista internacional de literatura i cultura medieval i moderna, núm. 9 / juny 2017 / pp. 144-164 ISSN: 2340 - 4841 doi:10.7203/SCRIPTA.9.9598 


\section{Juan Martínez Vinat. Virgen de la Misericordia, San Jerónimo y San Miguel: el origen del corporativismo sedero en la Valencia bajomedieval (1465-1518)}

fabricación de velos finos con mezclas de seda y algodón, como sucedió después en otras sederías españolas como Córdoba, Granada, Málaga, Murcia o Toledo (Navarro y Martínez 2016:26).

La denominación genérica de veleros que aparece en la documentación medieval para referirse a esta incipiente corporación se debe a su especialización en la confección de velos de seda, en concreto, de tejidos como el alquinal o toca que utilizaban las mujeres musulmanas para cubrirse la cabeza y la beatilla que portaban las mujeres cristianas sobre la cabeza para asistir a los oficios religiosos a modo de mantilla, además de otros complementos de seda que caracterizaban la indumentaria femenina valenciana en la época como son las muñequeras (canells) y las pecheras (davanteres). Más adelante, complementarían estos productos con el tejido de telas de hilo de seda para estandartes o cortinas (tercanells) y cedazos para tamizar (sedassos), entre otros (Navarro 2004:22).

Las primeras ordenanzas que reglaban esta producción y fundamentaban de manera oficial la creación de la cofradía de la Virgen de la Misericordia fueron aprobadas por privilegio de la reina Juana, lugarteniente general del monarca, el 15 de mayo de 1465 y confirmadas poco después por el Consell municipal en el mes de junio (Navarro 1992:45). ${ }^{3}$ Apenas dos años después, el colectivo alcanzaba representación política con la elección de dos consellers d'ofici en el gobierno del municipio. ${ }^{4}$ De esta forma, los sederos valencianos adquirían un status reconocido tanto por lo que se refiere a su estructura orgánica como a su participación política. Los estatutos fundacionales no fueron parcos a la hora de conceder gracias a la corporación, a semejanza de otros oficios menestrales valencianos (Martínez 2015a:206 y 2015b:259), permitiendo a los tejedores de velos tener señal propia, ${ }^{5}$ reunirse en capítulo, comprar casa social, elegir cargos y tener caja pecuniaria. Además, regulaban el ejercicio profesional, la contratación y el periodo de formación de los aprendices, la modalidad y las tasas del examen que daba acceso al grado de magisterio, y la imposición de penas a quienes enseñasen el oficio a esclavo, judío o moro, los extranjeros que abriesen tienda o las personas que se dedicasen a la venta ambulante.

El privilegio de 1465 facultaba también a los mayorales de la corporación a dictar nuevas ordenanzas en el futuro con la licencia previa del gobernador del reino, concesión que esgrimirían los tejedores de seda para lograr las sucesivas reformas de sus estatutos y que explican la aprobación de hasta siete normativas gremiales entre 1465 y 1518. La primera reforma de las ordenanzas fundacionales se produjo a raíz del privilegio otorgado en Monzón por Juan II el 20 de febrero de 1470 (Navarro

3 ARV. Real Cancillería, reg. 301, fols. 82r-86r; AMV. MC. A-38, fols. 11v-15r (1465-VI-23).

4AMV. MC. A-38, fol. 128v (1467-V-25). Los primeros consejeros del oficio de velers i seders con representación en el gobierno ciudadano fueron Joan García y Pau Mançana.

5 El emblema de la cofradía y oficio de veleros utilizado en sus estandartes representaba a la Virgen extendiendo su manto sobre un telar. Al tratarse de una cofradía fundada por menestrales de origen judeo-converso no resulta extraño la elección de dicho patronazgo que muestra a la Madre de Dios en actitud caritativa protegiendo al oficio, manifestando públicamente la convicción religiosa de los conversos al cristianismo. 
Juan Martínez Vinat. Virgen de la Misericordia, San Jerónimo y San Miguel: el origen del corporativismo sedero en la Valencia bajomedieval (1465-1518)

1992:46 y 1996). ${ }^{6}$ En ellas se da muestra del aumento de menestrales sederos en la ciudad, por lo que, a su juicio, el reconocimiento profesional debía ir acompañado de algunas prerrogativas como la exención del derecho de peaje que ya disfrutaban otros oficios de la ciudad. Al mismo tiempo, se prohibía el trabajo a domicilio en un claro intento de controlar la producción y la venta, y se aumentaban considerablemente las tasas del examen que pasaban de 30 a 100 sueldos, dispensando del pago a los hijos de maestros. Por otro lado, los capítulos concedidos en 1470 ampliaban la nómina de productos que podían elaborar con la inclusión de las manufacturas de algodón destinadas a la indumentaria femenina y limitaban el número de obreros en los talleres a dos por maestro, tratando de corregir las desigualdades socio-económicas entre los miembros del oficio.

Las terceras ordenanzas concedidas a los tejedores de velos serían aprobadas el 23 de enero de 1477 por las autoridades municipales de Valencia (Navarro 1992:46 y 1996). ${ }^{7}$ La preocupación del oficio continuaba siendo el control productivo y comercial, ya reglado en los estatutos anteriores, de ahí que se reiterara la obligación de tejer los productos en la casa o taller del maestro y se prohibiese la adquisición de sedas baratas a miembros externos al oficio. Igualmente, con el fin de garantizar la estabilidad de sus miembros, las ordenanzas facultaban a los mayorales a dar faena a los maestros empobrecidos, tratando de evitar así la injerencia de agentes externos que trastocaban el monopolio corporativo mediante encargos a domicilio, prohibidos desde 1470.

Dos años después, el 16 de febrero de $1479,{ }^{8}$ el Consell promulgaba nuevas ordenanzas para los tejedores de seda en virtud de determinados cambios en la moda del vestir y las novedades técnicas que habían asumido tanto los veleros como un nuevo grupo profesional que emerge en este momento, los velluters o terciopeleros (Navarro 1992:48 y 1996). En este sentido, los estatutos se refieren a la implantación masiva de la torcedura del hilo de seda a torno, una innovación tecnológica que proporcionaba mayor longitud y consistencia a las tramas y que se complementaba con el hilado tradicional de fibra en rama, coexistiendo ambas técnicas. La presencia de más de doscientos tornos funcionando en la ciudad en 1479 dan prueba de ello. Además, la irrupción del gremio de velluters en la ciudad, colectivo que acabaría asumiendo el liderazgo del sector, nos permite situar el año 1479 como fecha del despegue de la industria sedera en Valencia. De hecho, en este momento, el colectivo de artesanos de la seda superaba el millar de familias en una ciudad cuya población rondaba los 70.000 habitantes (Navarro y Martínez 2016:27).

Junto a las novedades técnicas, las cuartas ordenanzas reglaban el periodo de formación de los aprendices en cuatro años, más uno de oficialazgo, y se fijaba la edad mínima de acceso al examen

6 Archivo del Arte Mayor de la Seda de Valencia (AAMSV), 1, Pergaminos, nº 14. Copia inserta en el privilegio de Felipe II (1564-III-23).

7 AMV. MC. A-40, fols. 321v-324r.

8 AMV. MC. A-41, fols. 204r-208r.

SCRIPTA, Revista internacional de literatura i cultura medieval i moderna, núm. 9 / juny 2017 / pp. 144-164 ISSN: 2340 - 4841 doi:10.7203/SCRIPTA.9.9598 
Juan Martínez Vinat. Virgen de la Misericordia, San Jerónimo y San Miguel: el origen del corporativismo sedero en la Valencia bajomedieval (1465-1518)

en 20 años, prohibiendo abrir telar propio a miembros no examinados. Durante las siguientes dos décadas se producirá un silencio documental ininterrumpido hasta la aprobación de nuevos capítulos por parte del gobierno municipal el 30 de julio de 1499 (Navarro 1996:34). ${ }^{9}$ En este caso, las ordenanzas daban cuenta de otra innovación con la elaboración de telas de rodeos, una nueva tipología productiva sobre la que se imponía un límite de dos telares por maestro, frente al número ilimitado que gozaban el resto de manufacturas.

En el primer cuarto del siglo XVI los tejedores de seda todavía recibirían dos nuevas disposiciones gremiales. Las sextas ordenanzas el 29 de abril de $1506^{10}$ que reglamentaban la comercialización de los productos y reiteraban la prohibición de la venta a domicilio, y las séptimas el 30 de enero de 1518. Estas últimas reglas restringían la venta de tejidos únicamente a los maestros examinados, dejando fuera a los obreros, y retiraban a las mujeres su derecho de acceso al grado de magisterio, aunque fueran hijas de maestros, con el fin de evitar que tras su casamiento algunos miembros ajenos a la corporación pasasen a controlar los telares (Navarro 1996:35).

En definitiva, el ciclo ordenancista de la primera institución corporativa de la seda en Valencia, iniciado en 1465 con la creación de la cofradía de la Virgen de la Misericordia de tejedores de velos, delimita claramente la primera fase del despegue de la industria sedera en la Valencia del siglo XV. Una primera etapa que deriva de la pervivencia de la tradición sedera musulmana, asumida y conservada por menestrales judeo-conversos y mudéjares, pero que tras su reconocimiento institucional como corporación acabaría por desarrollar sus propias dinámicas en una clara tendencia hacia el monopolio productivo y comercial. La regulación del trabajo, la elección de cargos, el derecho de reunión, la contratación, el periodo de formación, el examen, la praxis del taller, la relación entre maestros y oficiales, el control del fraude o la exención de determinados impuestos, constituyen, como hemos visto, algunos de los privilegios con los que contó la primera corporación sedera valenciana reconocida de manera oficial. La consolidación de la industria de la seda en la capital del reino, no obstante, deberá aguardar a una segunda fase que se inicia en 1479 con la creación de la cofradía de San Jerónimo del Art de velluters.

\section{La cofradía de San Jerónimo del Art de velluters (1477-1518).}

Poco después de constituirse la cofradía y oficio de tejedores de velos de seda, en los años setenta del siglo XV, la inmigración de varios centenares de sederos procedentes de Génova supuso la implantación paralela del arte de tejer velluto terciopelo de seda en Valencia, de gran tradición en Italia (Arte dei Vellutier), dando origen al nacimiento del gremio conocido como Art dels velluters, con diversos estatutos aprobados entre 1477 y 1518. Desde entonces Valencia lideró la industria textil sedera de la Península Ibérica en época de los Reyes Católicos y durante todo el siglo XVI

9 AMV. MC. A-50, fols. 31v-33r.

10 AMV. MC. A-53, fol. 142r.

SCRIPTA, Revista internacional de literatura i cultura medieval i moderna, núm. 9 / juny 2017 / pp. 144-164 ISSN: 2340 - 4841 doi:10.7203/SCRIPTA.9.9598 
Juan Martínez Vinat. Virgen de la Misericordia, San Jerónimo y San Miguel: el origen del corporativismo sedero en la Valencia bajomedieval (1465-1518)

con más de un millar de familias artesanas que, amparadas por la corporación, trabajaban en cientos de telares y tornos identificados en la documentación conservada. La manufactura local quedó dividida por consiguiente en dos ofertas de productos complementarias: la obra blanca de seda de vieja tradición musulmana y judeo-conversa, y la nueva obra tintada de paños de seda pura para vestir (terciopelos, satenes, damascos, brocados, chamelotes, tafetanes, etc.).

En distintas fuentes documentales se han podido identificar más de 2.500 artesanos de la seda de diversos oficios entre 1450 y 1525, de los cuales alrededor de 2.000 eran velluters y un $40 \%$ de ellos extranjeros del reino (Navarro 1999). En este sentido, buena prueba del arranque sin precedentes de la sedería valenciana sería el número ascendente de telares de terciopelos, satenes y damascos instalados en Valencia, que pasaron de ser 172 para el año 1479, en plena erección corporativa, hasta llegar a alcanzar los 1.200 telares en 1519, en vísperas de las Germanías. Todo ello contribuyó a configurar un auténtico barrio artesanal -barri de Velluters- que modificaría sustancialmente el mapa topográfico de la capital del reino (Navarro y Martínez 2016:29).

Ahora bien, la particularidad de la cofradía y Arte de velluters deriva de la riqueza de su fondo gremial. Los Llibres de Dates $i$ Rebudes conservados en el Archivo del Colegio del Arte Mayor de la Seda de Valencia (AAMSV, sign. 2.1/1-2.1/323), reformado recientemente, recogen la contabilidad de esta corporación desde 1479 hasta 1856 (Aleixandre 1987), presentándose como fuente privilegiada para analizar tanto el desarrollo profesional del colectivo como la vertiente asistencial de su cofradía, plasmados a través de los ingresos y gastos procedentes de los capítulos y comidas, exámenes, multas, festividades, caridades y sepulturas. La posibilidad de contar con una serie casi ininterrumpida que abarca desde el ocaso de la Edad Media hasta la abolición de los gremios ocurrida a mediados del siglo XIX nos permite a día de hoy ahondar en la organización interna y en la vida cotidiana de una corporación dinámica y en constante desarrollo, trazando un proceso de institucionalización y adquisición de competencias gremiales que va más allá de la información de tipo normativo que aportaban los estatutos y ordenanzas del oficio (Martínez 2016:144).

Si bien el gremio de velluters ha sido ampliamente estudiado como corporación profesional tanto en el periodo medieval como en época moderna (Navarro 1992, 1996, 1999, 2000 y 2011; Franch 2012), la función benéfico-asistencial del colectivo apenas ha despertado el interés de los historiadores, siguiendo un tratamiento diferenciado entre cofradía y gremio que no responde a una realidad histórica. Y es que en la praxis ambas asociaciones constituyeron las dos vertientes -devocional y profesional- de una única institución corporativa, difícil de separar una de otra en la práctica documental (Martínez 2016:143). En este sentido, la reciente publicación de un libro que aborda, de manera singular, la historia asistencial, caritativa y funeraria del oficio de velluters de Valencia completaría la trayectoria investigadora sobre una asociación de tipo religioso-gremial, como era habitual en la época, que se distingue por ser una de las más antiguas en activo: la cofradía de San Jerónimo de Valencia (Navarro y Martínez 2016).

Por lo que respecta a las normativas que sancionaron la existencia legal y el desarrollo corporativo 
Juan Martínez Vinat. Virgen de la Misericordia, San Jerónimo y San Miguel: el origen del corporativismo sedero en la Valencia bajomedieval (1465-1518)

del oficio de velluters sorprende sin duda el número elevado de ordenanzas concedidas por el gobierno local, la autoridad real o, en su defecto, la gobernación del reino, situando al colectivo entre los más privilegiados de la Valencia medieval y moderna. En total, se han localizado 16 estatutos, reformas y adiciones para el periodo comprendido entre 1477 y 1518, además de otros documentos interesantes, como la concordia firmada entre la cofradía y el monasterio de San Jerónimo de Cotalba en 1483, o el acta notarial de la compra de la casa social en 1494 (Martínez 2016:144).

El punto de partida se sitúa con la erección de la asociación benéfico-profesional. En concreto, el 18 de octubre de 1477 cincuenta y seis maestros velluters, reunidos en la casa del genovés Lazzaro Negro, sita en la calle de las Barcas de Valencia, firmaron ante el notario Bernat Sant Feliu el acta de fundación de la Lloable Confraria o Almoina de l'Ofici de Velluters bajo la advocación de San Jerónimo (Navarro y Martínez 2016:30). Se trata de una unión que carece todavía de reconocimiento institucional, pero en cuyos capítulos se delimita la organización y el funcionamiento de los profesionales del offici de velluters, cetiners, texidors de domasos, de brocats, velluts, vellutats e picholats. Prueba de ello sería la reglamentación del sistema de elección de cargos (mayorales, clavario, escribano y veedores), la configuración de una estructura corporativa mixta caracterizada por el turno de mandatos entre los maestros valencianos y extranjeros, la regulación de las cuotas, los capítulos, la tipología y calidad de los tejidos, el límite de telares por maestro, la contratación y el periodo de formación de los aprendices, la modalidad y las tasas del examen, la prohibición de abrir telares a miembros no examinados, etc.

El reconocimiento oficial y la sanción de los primeros capítulos se produciría, con ligeras modificaciones, el 16 de febrero de $1479^{11}$ con la aprobación del Consell y, unos meses después, con el privilegio otorgado por Fernando el Católico el 13 de octubre de 1479 (Navarro, 2011), cuyo original ha sido hallado recientemente en el Archivo de la Diputación de Valencia (Navarro 2016). ${ }^{12}$ La aprobación real suponía además el máximo reconocimiento social para la profesión, con el paso de oficio a arte, lo que les permitiría disfrutar de las mismas prerrogativas institucionales que gozaban otras artes de Valencia como los boticarios, cirujanos o notarios (Martínez 2015a:206). La primera reforma de las mismas tendría lugar apenas un año después, con las segundas ordenanzas aprobadas por el gobierno municipal el 9 de septiembre de $1480^{13}$ (Navarro 2011:30).

Otra fecha clave para la institucionalización corporativa sería el año 1483, no sólo porque se dictaron

11 AMV. MC. A-41, fols. 198v-204r.

12 Archivo de la Diputación de Valencia (ADV). Pergamino, n 525. Otras copias pueden verse en: Archivo de la Corona de Aragón (ACA). Real Cancillería, reg. 3635, fols. 85r-89r; AAMSV, 1, Pergaminos, nº 8 (traslado notarial, Jaume Pellicer, 1514); Hispanic Society of America (HSA). Ms. HC:NS1/814, fols. 20r-21v.

13 AMV. MC. A-42, fols. 32v-37r; HSA. Ms. HC:NS1/814, fols. 11r-18v.

SCRIPTA, Revista internacional de literatura i cultura medieval i moderna, núm. 9 / juny 2017 / pp. 144-164 ISSN: 2340 - 4841 doi:10.7203/SCRIPTA.9.9598 
Juan Martínez Vinat. Virgen de la Misericordia, San Jerónimo y San Miguel: el origen del corporativismo sedero en la Valencia bajomedieval (1465-1518)

las terceras normativas del Consell el 18 de febrero ${ }^{14}$ en las que se adoptaban medidas contra el fraude en los tejidos, imponiendo la obligación de presentar las telas ante el Mostassaf, sino porque el 20 de agosto el gobernador del reino, Lluís Cabanyelles, sancionaba las primeras ordenanzas plenamente confraternales de la cofradía de San Jerónimo, regulando sus prácticas devocionales, funerarias y asistenciales e imponiendo la obligación a todos los maestros velluters a pertenecer a la cofradía. ${ }^{15}$ Poco después, en el mes de septiembre de 1483 los mayorales de la cofradía firmaban una concordia con el prior y los frailes del monasterio de San Jerónimo de Cotalba en Alfahuir (Gandía) para realizar sus fiestas y sepulturas en una capilla o iglesia de San Jerónimo, propiedad de la orden, que se ubicaba en el camí de Sent Vicent, fuera de las murallas de la ciudad de Valencia (Martínez 2016:145, Navarro y Martínez 2016:121). ${ }^{16}$

Las ordenanzas confraternales de 1483 autorizaban al mismo tiempo a los cofrades a comprar casa propia. En este sentido, tras procurarse la capilla de la iglesia de San Vicente, el patrimonio de la asociación se ampliaba con la adquisición de un centro para las asambleas corporativas. En el año 1494 se produjo la compra por el precio de 9.600 sueldos de la casa confraternal que después se ha conservado como sede del Colegio del Arte Mayor de la Seda de Valencia, situada en la parroquia de San Martín, en la actual calle del Hospital, recientemente reformada (Pérez 2013:22, Navarro y Martínez 2016:83). ${ }^{17}$

En relación a la vertiente profesional, los velluters recibirían nuevas ordenanzas municipales el 23 de noviembre de 1490, las cuales versaban a grosso modo de las tramas prohibidas, la relación entre maestros, oficiales y aprendices, las obligaciones particulares de los extranjeros, los privilegios de los hijos de maestro y la prohibición de enseñar el oficio a esclavos o infieles (Navarro 2011:36). ${ }^{18}$ Una nueva disposición del Consell concedida el 12 de marzo de 1495 modificaba sustancialmente las tasas del examen que pagaban los obreros para acceder al grado de magisterio, reduciendo los importes a los naturales de la ciudad y el reino de Valencia (de 100 a 50 sueldos), a los habitantes de la Corona de Aragón (de 200 a 100 sueldos) y a los extranjeros (de 300 a 150 sueldos). ${ }^{19}$ La reducción de las tasas, sin embargo, no debió ser acatada por los oficiales del gremio, de ahí que los jurados reiterasen en el año 1501 el cumplimiento de la disposición. ${ }^{20}$

14 AMV. MC. A-43, fols. 92r-94r; HSA. Ms. HC:NS1/814, fols. 22r-25v.

15 ARV. Gobernación, no 2366, m. 4, f. 16v; nº 2368, m. 27, f. 23r-26v; HSA. Ms. HC:NS1/814, f. 33r-40v.

16 AAMSV, Leg. 3.3.1., Procesos, no 42, fols. 46r-76r. Traslado notarial realizado en 1595.

17 Archivo de Protocolos del Corpus Christi de Valencia (APCCV). Protocolos. Lluis Gaçet, no 23.054 (1494-IX-26. Valencia).

18 AMV. MC. A-46, fol. 46v; HSA. Ms. HC:NS1/814, fols. 25v-32v. El autor data las ordenanzas municipales por error en 1491, no obstante en el documento puede leerse claramente en l'any de la nativitat de nostre Senyor MCCCCLXXXX.

19 AMV. MC. A-48, fols. 200v-201v; HSA. Ms. HC:NS1/814, fols. 41r-42r.

20 HSA. Ms. HC:NS1/814, fol. 42r.

SCRIPTA, Revista internacional de literatura i cultura medieval i moderna, núm. 9 / juny 2017 / pp. 144-164 ISSN: 2340 - 4841 doi:10.7203/SCRIPTA.9.9598 
Juan Martínez Vinat. Virgen de la Misericordia, San Jerónimo y San Miguel: el origen del corporativismo sedero en la Valencia bajomedieval (1465-1518)

A principios del siglo XVI, antes de las Germanías, el gremio de velluters todavía recibiría siete nuevos estatutos. El 28 de septiembre de 1501 se aprobaba un nuevo capítulo sobre la manera en que se debían tejer los damascos. ${ }^{21} \mathrm{El} 6$ de octubre de 1507 el gobernador del reino aprobaba nuevas disposiciones sobre el sistema de contratación de los aprendices. ${ }^{22}$ En 1511 el Consell dictaba nuevas ordenanzas sobre el teñido de las manufacturas, a raíz de un pleito surgido el año anterior entre los velluters y los tintorers de seda de la ciudad, una corporación que recordemos se había erigido en 1506. ${ }^{23}$ Más tarde, el 28 de septiembre de 1514 el gobernador promulgaba, con pregón público, nuevos reglamentos que modificaban los sistemas de elección de mayorales, oidores de cuentas y veedores, concediendo mayor protagonismo a los extranjeros (axi castellans com spanyols e genovesos e italians, $e$ altres nacions), y obligando a los aprendices a cumplir el tiempo de contrato de cinco años firmado con los maestros (Navarro 2011:37). ${ }^{24}$

Apenas unos días después, el 5 de octubre de 1514, el gremio sorprendía renunciando a su capacidad de autogobierno ante el municipio, dejando sin efecto la prerrogativa concedida por Fernando el Católico en 1479 de poder dictar nuevas ordenanzas. ${ }^{25}$ Los motivos de tal proceder no están claros, el documento no especifica razón alguna salvo considerar los derechos ésser danyosos o molt prejudicials al dit offici en moltes maneres que per brevitat se callen. El silencio escondía una división interna surgida en el seno del gremio con dos facciones enfrentadas: una formada por maestros locales y otra encabezada por algunos genoveses que habían visto reforzada su posición con las ordenanzas del 28 de septiembre. De hecho, los mismos mayorales que renunciaban ante el Consell presentaban un requerimiento al gobernador del reino el 21 de noviembre de 1514 para poder congregar a una parte de la corporación que són de la lur opinió e voluntat y elegir un síndico que acudiese a la corte regia para defender sus intereses. ${ }^{26}$ La súplica, rechazada con anterioridad, no sería admitida en la provisión dictada por el gobernador el 24 de noviembre, alegando que los pretendidos mayorales habían finalizado su mandato el pasado 30 de septiembre, festividad de San Jerónimo, por lo que carecían de legitimidad. En cambio, la parte contraria, la de los genoveses, se había reunido con la licencia del gobernador y la presencia de uno de sus asesores ordinarios, evidenciando que la corte del gobernador se había decantado por el sector encabezado por los italianos. Las diferencias intra-corporativas se solventarían con el triunfo del bando genovés y la situación volvería a la normalidad institucional. Todavía el 30 de enero de 1518 se aprobarían cuatro nuevos capítulos sobre la torcedura de seda (Navarro 1996:43).

21 HSA. Ms. HC:NS1/814, fols. 42v-43r.

22 HSA. Ms. HC:NS1/814, fols. 18v-19r.

23 AMV. MC. A-54, fols. 600r-601v; HSA. Ms. HC:NS1/814, fols. 60v-63v.

24 HSA. Ms. HC:NS1/814, fols. 44r-50v. El documento aparece datado erróneamente el 28 de septiembre de 1510 en la referencia bibliográfica, en lugar de 1514.

25 AMV. MC. A-56, fols, 120r-121r.

26 ARV. Gobernación, no 2441, m. 5, fol. 45r; m. 8, fols. 33v-34v.

SCRIPTA, Revista internacional de literatura i cultura medieval i moderna, núm. 9 / juny 2017 / pp. $144-164$ ISSN: 2340 - 4841 doi:10.7203/SCRIPTA.9.9598 


\section{Juan Martínez Vinat. Virgen de la Misericordia, San Jerónimo y San Miguel: el origen del corporativismo sedero en la Valencia bajomedieval (1465-1518)}

\section{Tintoreros de seda. La cofradía de San Miguel (1497-1511).}

Junto a los tejedores de velos y los terciopeleros, una tercera corporación vinculada a la sedería valenciana obtuvo reconocimiento institucional al final del periodo bajomedieval: los tintoreros de seda. Probablemente, hasta ese momento, los artesanos dedicados a los tintes de seda habrían formado parte de las dos corporaciones sederas preexistentes, especialmente del Art de velluters, quien desde su erección en 1479 había asumido competencias monopolísticas en todas las ramas del sector, constituyéndose como el principal colectivo sedero de la capital del reino. ${ }^{27}$ No obstante, el grado de especialización adquirido por algunos miembros, el aumento considerable del número de tintoreros y la falta de promoción dentro del colectivo de terciopeleros propiciaría la separación y la declaración de oficio independiente. ${ }^{28}$

El 28 de septiembre de 1497 algunos prohombres del offici dels sedés e tintorés de seda de la ciudad de Valencia solicitaron al Consell la aprobación de una serie de capítulos que regulaba la práctica profesional y las funciones benéfico-asistenciales de su cofradía. Siguiendo el protocolo, el consejo municipal remitió el asunto al Consell Secret, quedando pospuesta la promulgación de las normativas hasta el 29 de abril de $1506 .{ }^{29}$ No es habitual que, sin causa aparente, el gobierno ciudadano retrasase tanto la sanción de unos estatutos profesionales, casi ocho años después de que los prohombres tintoreros presentasen formalmente la solicitud. Aunque la documentación oficial no ofrece información al respecto, podemos intuir que detrás de la demora se escondía la presión ejercida por parte del oficio de velluters y su cofradía de San Jerónimo, que bajo ninguna circunstancia vería con buenos ojos la erección de un nuevo colectivo sedero. Las tensiones y litigios posteriores entre ambas asociaciones parecen confirmar esta idea (Navarro y Martínez 2016:71). ${ }^{30}$ Tampoco parece casualidad que la solicitud corporativa de los tintoreros de seda de Valencia se produjera justo un año después de que en Génova se aprobase la normativa del Arte dei Tintori di Seta (Massa 1981:69, Navarro 1996:47), sobre todo si tenemos en cuenta el peso demográfico de los sederos ligures en Valencia.

Fuere como fuere, los tintoreros de seda obtuvieron en el mes de abril la aprobación municipal de sus estatutos con facultad para fundar oficio y cofradía propia bajo la advocación del arcángel San

27 Los tres representantes que ejercen como síndicos del oficio de sederos y tintoreros, Agostini de Francisqui, Pere Vicent y Leonard Jordi, aparecen registrados como velluters o seders en la documentación notarial contemporánea.

28 Los motivos alegados por los tintoreros de seda para la aprobación de sus ordenanzas fundacionales incidían en el incremento del número de profesionales y su especialización: com lo dit offici de sedés e tintorés de sedes sia vuy molt gran, axí nombres de persones com en lo exercici de aquell, que per mar e per terra de les dites obres se fa e se acostuma fer grans mercaderies per moltes parts (...). ARV. Real Cancillería, reg. 312, fol. 266r.

29 AMV. MC. A-53, fol. 142r.

30 En el Llibre de Dates e Rebudes del Art de velluters de 1512 se registra un pago al síndico de la corporación per hordenar buns capitols contra los tintorers en deffenció del offici. Cfr. AAMSV. Lb. 2.1.10, s.f.

SCRIPTA, Revista internacional de literatura i cultura medieval i moderna, núm. 9 / juny 2017 / pp. 144-164 ISSN: 2340 - 4841 doi:10.7203/SCRIPTA.9.9598 


\section{Juan Martínez Vinat. Virgen de la Misericordia, San Jerónimo y San Miguel: el origen del corporativismo sedero en la Valencia bajomedieval (1465-1518)}

Miguel, ${ }^{31}$ ordenanzas que serían confirmadas por el monarca Fernando el Católico con privilegio dado en Zaragoza en el mes de julio de $1506 .{ }^{32}$ Los estatutos fundacionales guardan muchas similitudes con los reglamentos de los tejedores de seda: les permitían tener divisa propia con la imagen patronal para portar en sus banderas gremiales cuando desfilasen junto a los demás oficios en las entradas de reyes, Corpus Christi y demás procesiones cívico-religiosas (cap. I y II), reunirse en capítulo y comprar casa social donde poder tratar sus asuntos y elegir a los mayorales, clavario y veedores (cap. III, IV y XIV). Regulaban las funciones y el salario de los andadores o mensajeros (cap. XII), la rendición de cuentas de los oficiales (cap. XIII), la contratación y el periodo de formación de cuatro años de los aprendices (cap. X y XI), la edad mínima de 20 años de acceso al grado de magisterio y las tasas de cien sueldos del examen, estando exentos los hijos de maestros (cap. V y XVI), la calidad de los tintes (cap. VIII y IX) y el trabajo por encargo (cap. XVII y XVIII). Prohibían abrir tienda, taller o tinte a obreros no examinados (cap. V y XIX) y enseñar el oficio a moro o infiel (cap. VI). Finalmente, se les reconocía el derecho de reunión y la facultad para aprobar nuevas reglas siempre que obtuvieran previamente licencia del gobernador del reino y lo notificaran a los jurados de la ciudad (cap. XX).

Una vez obtenido el reconocimiento institucional y la confirmación de sus ordenanzas, los tintoreros de seda de Valencia comenzaron su actividad como corporación independiente a pesar de los recelos mostrados por el oficio de velluters, quien en 1510 promovería un pleito contra los tintorers de seda acusando al nuevo oficio de injerencia profesional y denunciando negligencias cometidas en las técnicas de tintado de tejidos de seda (Navarro y Martínez 2016:45). Una disposición ordenada por el Consell municipal el 27 de marzo de 1511 pondría fin al conflicto. ${ }^{33}$ Para corregir las diferencias se regularon las competencias de ambas corporaciones y se dictaron pautas que reglamentaban la forma de teñir las sedas, tratando de evitar que se cometieran fraudes en la elaboración de los tejidos.

Tras la revuelta ciudadana de las Germanías (1519-1523), en la que participaron muchos artesanos de la seda, la represión afectaría al conjunto de colectivos, especialmente a los velluters, con la reducción del número de profesionales y telares (de 1.200 a 400). La industria y las corporaciones sederas valencianas entrarían en crisis a mediados del siglo XVI. La represión monárquica, el fraude contra las disposiciones técnicas, la entrada de seda americana o el impulso de la actividad sedera en Toledo, constituirían las causas principales del declive según Germán Navarro (2011:37), frenando temporalmente un impulso que se había iniciado en 1465 y que configuraba el origen y desarrollo

31 La elección de la advocación del arcángel San Miguel para la cofradía de tintoreros de seda tiene precedentes en el corporativismo valenciano. San Miguel era patrón de las cofradías de maestros pelaires y estibadores del puerto (Bastexes del Grau) desde la segunda mitad del siglo XIV (Martínez 2016b). Curiosamente, la festividad se celebraba el 29 de septiembre, coincidiendo con las fiestas patronales de las corporaciones sederas de la Virgen de la Misericordia (24 de septiembre) y San Jerónimo (30 de septiembre).

32 ARV. Real Cancillería, reg. 312, fols. 266r-273r. La transcripción de las mismas puede verse en el apéndice documental.

33 AMV. MC. A-54, fols. 600r-601v; HSA. Ms. HC:NS1/814, fols. 60v-63v.

SCRIPTA, Revista internacional de literatura i cultura medieval i moderna, núm. 9 / juny 2017 / pp. 144-164 ISSN: 2340 - 4841 doi:10.7203/SCRIPTA.9.9598 
Juan Martínez Vinat. Virgen de la Misericordia, San Jerónimo y San Miguel: el origen del corporativismo sedero en la Valencia bajomedieval (1465-1518)

del corporativismo sedero en Valencia.

\section{Bibliografía}

Aleixandre Tena, F. (1987). Catálogo del Archivo del Colegio del Arte Mayor de la Seda, Valencia, Colegio del Arte Mayor de la Seda de Valencia.

Franch Benavent, R. (2012). Del «vellut» al espolín. Estudios sobre la industria valenciana de la seda en la edad moderna, Valencia, Obrapropia.

Martínez Vinat, J. (2015a). «Corporaciones y gremios», en Ciudad y Reino. Claves del Siglo de Oro valenciano, coord. R. Narbona Vizcaíno, Valencia, Ajuntament de València, pp. 206-208.

Martínez Vinat, J. (2015b). «La organización confraternal», en Ciudady Reino. Claves del Siglo de Oro valenciano, coord. R. Narbona Vizcaíno, Valencia, Ajuntament de València, pp. 259-265.

Martínez Vinat, J. (2016). «La cofradía de San Jerónimo del Art de Velluters de Valencia a través de su contabilidad (1479-1524)» en P. Iradiel, G. Navarro, D. Igual y C. Villanueva (eds.), Identidades urbanas Corona de Aragón-Italia. Redes económicas, estructuras institucionales, funciones políticas (siglos XIVXV), Zaragoza, PUZ, pp. 143-161.

Massa, P. (1981), La fabbrica dei velluti genovesi da Genova a Zoagli, Génova, Libri Scheiwiller.

Navarro Espinach, G. (1992). El despegue de la industria sedera en la Valencia del siglo XV, Valencia, Consell Valencià de Cultura, Generalitat Valenciana.

Navarro Espinach, G. (1996). El Col legi de l'Art Major de la Seda de València, Valencia, Consell Valencià de Cultura, Generalitat Valenciana.

Navarro Espinach, G. (1999). Los orígenes de la sedería valenciana (siglos XV-XVI), Ajuntament de València.

Navarro Espinach, G. (2000). «L'Art de Velluters de València, de la fundació a les Germanies» en Ll. Virós (Ed.), Organització del treball preindustrial: confraries $i$ oficis, Barcelona, Publicacions de l’Abadia de Montserrat, pp. 81-90.

Navarro Espinach, G. (2002). «Los musulmanes y la ruta de la seda entre Oriente y Occidente», en F. Nuez (ed.), La herencia árabe en la agricultura y el bienestar de Occidente, Universitat Politècnica de València, pp. 282-328.

Navarro Espinach, G. (2004). «El arte de la seda en el Mediterráneo medieval», En la España Medieval. Revista del Departamento de Historia Medieval de la Universidad Complutense de Madrid, $\mathrm{n}^{\circ}$ 27, pp. 5-51.

Navarro Espinach, G. (2011). «Las ordenanzas más antiguas de velluters, 1479-1491. Auge del comercio sedero y edificación de la Lonja Nueva de Valencia» en el catálogo de la exposición L'Art dels Velluters. Sedería de los siglos XV-XVI, Valencia, pp. 23-48 (English Translation: pp. 85-92).

Navarro Espinach, G. (2016). El privilegi del rei Ferran II d'Aragó per a l'Art de Velluters de València 
Juan Martínez Vinat. Virgen de la Misericordia, San Jerónimo y San Miguel: el origen del corporativismo sedero en la Valencia bajomedieval (1465-1518)

(1479), València, Institució Alfons el Magnànim, Diputació de València.

Navarro Espinach, G. - Martínez Vinat, J. (2016). La cofradía de San Jerónimo del Art de Velluters de Valencia. Fundación y primeros años (1477-1524), Valencia, Agència Valenciana del Turisme.

Pérez Guillén, I. V. (2013). La Casa del Colegio del Arte Mayor de la Seda de Valenciay su Reino, Ajuntament de València.

Teixidor, J. (1755). Capillas y sepulturas del Real Convento de Predicadores de Valencia, ed. facsímil de Acción Bibliográfica Valenciana (1949), t. II, pp. 120-121.

\section{Apéndice documental}

\section{6, julio. Zaragoza.}

Fernando el Católico confirma las ordenanzas fundacionales otorgadas por el Consell Secret en el mes de abril a la cofradia y oficio de sederos y tintoreros de seda de Valencia. Los estatutos les permiten tener señaly bandera con la imagen de San Miguel, reunirse en capitulo y poseer casa social; establecen el sistema de elección de cargos, la rendición de cuentas, las funciones y salario de andadores, el periodo de formación de aprendices, el control de la contratación, la edad minima y las tasas del examen; probiben abrir tinte a obrero no examinado y enseñar el ofici a moro o infiel; regulan la calidad de los productos, las cuotas de los capitulos, los privilegios de los hijos de maestro y facultan a los mayorales para reunirse y aprobar nuevas ordenanzas con la licencia de los oficiales reales.

ARV. Real Cancillería, reg. 312, fols. 266r-273r.

Offici de tintorers de seda.

Nos Ferdinandus, etc. Exbibita et reverenter presentata fuerint coram nobis pro parte vestri dilectorum et fidelium nostrorum procerum officii vulgo dicti dels sedés e tintorés de la seda civitatis nostre Valencie ordinacionem et capitula inter vos inserita, facta et concordata, ac per iuratis, racionalem et sindicum dicte civitatis decretata, auctorizata, confirmata et concessa tenoris sequentis:

En nom de Jesús e de la gloriosíssima Verge Maria, mare sua, vinga en memòria en lo sdevenidor a tots los qui legir ho volran que en lo any de la nativitat de nostre Senyor Déu Jesu Christ mil cinchcents e sis, dimecres comptant vintinou del mes de abril, los magnífichs mossén Joan Marrades, cavaller, en Pere Guillem Garcia, ciutadà, mossén Perot Crespí de Valdaura, cavaller e Nicholau Benet d'Alpont, ciutadà, quatre dels magnífichs jurats en l'any present de la insigne ciutat de València, ensemps ab los magnífichs en Onofre Çahera e en Joan Alegre, ciutadans absents de aquest acte, micer Baltasar de Gallac, en micer Martí Eximeno Ros, doctors en cascun dret, altres dels advocats de la dita ciutat, e en Bernat Dassió, síndic de la present ciutat de València, ajustats e congregats tots los desús dits en la cambra de consell secret de la sala de la dita ciutat, per lo poder a ells atribuit e donat per lo consell general celebrat en la sala de la dita ciutat a vintivuyt del mes de 
Juan Martínez Vinat. Virgen de la Misericordia, San Jerónimo y San Miguel: el origen del corporativismo sedero en la Valencia bajomedieval (1465-1518)

setembre del any de la nativitat de nostre Senyor Déu mil quatrecents noranta set, considerat e per part dels prohòmens del offici dels sedés e tintorés de seda de la dita ciutat són stats presentats certs capítols als dits magnífichs jurats, advocat e síndich de la dita ciutat desús comemorats, los quals capítols son stats ordenats per los prohòmens e altres singulars del dit offici, demanant de gràcia als desús dits magnífichs jurats, advocat e síndich que los dits capítols e cascú de aquells auctorizen e decreten, e proveeixquen e manen publicar per la dita ciutat e lochs acostumats de aquella, e vista e oyda la dita petició, e considerats que los dits capítols e cascú de aquells són ornament e honor de la república de la dita ciutat, e encara útils e profitosos per al poble de la universitat de la dita ciutat de València e conservació e augment del dit offici dels seders e tintorés de seda, en unitat e concòrdia, maturament e digesta, a beneplàcit emperò dels dits magnífichs jurats e Consell de la dita ciutat, los desús dits magnífichs jurats, advocats e síndich auctorizen e decreten los capítols e cascú de aquells, provehint e manant aquells ésser publicats e preconitzats ab veu de pública crida per la dita ciutat e lochs acostumats de aquella, perquè a tot hom sien universal e particular manifests, e per algú o alguns en lo sdevenidor ignorància no 's puixa ésser al legada, lo effecte, tenor e continència dels dits capítols són del serie e tenor inmediate següents:

En nom de nostre Senyor Déu omnipotent Pare e Fill e Sanct Sperit, e de la gloriosíssima Verge Maria, mare sua, special advocada de tots los feels christians, com sia cosa humana a amar, voler e desijar lo bé comú de tots generalment, e no obligar lo propi interés de cascú particularment, los pròmens del dit offici de sedés e tintorés de seda de la present ciutat de València demanen e volen los capítols següents, los quals redunden en gran profit e utilitat de la cosa pública de la dita ciutat de València e de tot lo regne de València, com lo dit offici de sedés e tintorés de sedes sia vuy molt gran, axí nombres de persones com en lo exercici de aquell, que per mar e per terra de les dites obres se fa e se acostuma fer grans mercaderies per moltes parts. E axí los drets ne són molt augmentats, per tant los dits pròmens supliquen e demanen a vosaltres, dits senyors de jurats e consell, per conservació del dit offici de sedés e tintorés de seda, vos plàcia provehir e atorgar, fer-ne e crehar offici de sedés e tintorés de seda ab les inmunitats e perrogatives que los altres officis de la present ciutat tenen asignats en los dits capítols e coses en aquell contengudes, los quals són del tenor e continènsia següents:

[1] Primerament, proveheixen e ordonen que attenent que los dits sedés e tintorés de seda són en gran nombre entre sí fassen offici e sien offici format, nomenant lo offici de sedés e tintorés de seda, e que sia donat a aquells e al dit offici e per al dit offici aquell senyal que als dits senyors de jurats, racional, advocats e síndichs plaurà. Lo qual senyal puixen e sien tenguts portar an bandera e penons, axí en sol lemnitats de entrades vengudes de la magestat del rey nostre senyor o de fill de aquell, o nativitats de aquells o de sos successors, com encara en altres festivitats acostumades fer per los officis de dita ciutat, com encara de la festa de Corpore Christi, e encara en altres festes e sol lemnitats segons que los altres officis de la dita ciutat són e han acostumat fet.

[II] Ítem més, proveheixen e ordonen que per quant lo dit offici de sedés e tintorés de seda té per 


\section{Juan Martínez Vinat. Virgen de la Misericordia, San Jerónimo y San Miguel: el origen del corporativismo sedero en la Valencia bajomedieval (1465-1518)}

advocat lo beneyt archàngel sanct Miquel, per ço proveheixen que aquells puixen portar an la sua bandera la ymatge del dit beneyt archàngel sanct Miquel e altres insígnies e coses del dit offici, e tenir devall la dita ymatge les coses pertanyents al dit offici per ornar e noblir aquell.

[III] Ítem més, proveheixen, statuexen e ordonen que lo dit offici de sedés e tintorés de seda, que no obstant qualsevol fur o privilegi prohibints ajusts o altre congregació sens licència de algun official, se puixe ajustar cascun any honestament tantes vegades quant a aquells serà benvist per tractar del dit offici e de les coses consernents a aquell, an aquells dies que al dit offici serà benvist deures ajustar segons les necessitats que occorreran al dit offici, e senyaladament en lo dia que s celebrarà la festivitat del dit benaventurat archàngel sanct Miquel en la casa hon se ajustarà lo dit offici, constituida en la dita present ciutat, la quals casa los done licència de haver e poder comprar aquella, e aprés tenir, possehir-la perpetualment per obs del dit offici e almoyna de aquell, en la qual dita casa se hage a fer cascun any la elecció de maiorals, clavari e vehedors, e altres officis necessaris al dit offici e al bon regiment de aquell segons devall se dirà.

[IV] Ítem, proveheixen, statuexen e ordonen que lo dit offici de sedés e tintorés de seda puixen fer elecció de clavari, maiorals e vehedors del dit offici per l'any present en aquesta manera, ço és, que attés que per los prohòmens del dit offici són stats elets en síndichs de aquell en Pere Vicent, en Leonard Jordi e en Agostini de Francisqui, los quals tenen notícia de totes les coses necessàries per al bé del dit offici e de la conservació de aquell, e axí aquells mills que tots altres coneixen les persones que tenen habilitat per a regir los dits officis, que la dita elecció de clavari, maiorals e veedors per a l'any present sia feta per aquells dits síndichs o per los dos de aquells ensemps ab quatre prohòmens del dit offici per aquells dits síndichs elegidors, en axí que aquells dits síndichs e los dits quatre prohòmens o la maior part de aquells, concordantment, facen elecció de quatre maiorals e de dos vehedors del dit offici per a l'any present, ço és, aquells del dit offici que aquells voldran e elegiran, emettent o a sa bona coneguda, en axí que de aquells quatre maiorals que per aquells dits síndichs e prohòmens seran stats nomenats e elegits, segons és dit, lo primer qui serà nomenat en cap serà clavari, e reeba e haia rebre totes les pecúnies pertanyents al dit offici en l'any de la sua clavaria, e que en aprés, en los anys sdevenidors e aprés següents, la dita elecció de clavari, maiorals e veedors del dit offici sia feta en la forma següent, ço és, que en lo endemà de la festa del dit beneventurat archàngel sanct Miquel los dits maiorals e vehedors elegiran, los quals dits clavari, maiorals e vehedors, concordantment o la maior part de aquells, elegeixquen e haien a elegir quatre maiorals e dos vehedors del dit ofici, ço és, aquells del dit offici que aquelles dits maiorals e prohòmens, o la major part de aquells volran e elegiran, remetent-ho a la llur bona coneguda, en axí que lo maioral en cap sia e haia ésser clavari de les peccúnies pertanyents al dit offici. E axí se faça e se haia de fer d'aquí avant cascun any perpetualment la dita elecció de clavari, maiorals e veedors en lo dit offici en lo dit dia.

[V] Ítem, statuhexen e ordenen que qualsevol obrer del dit offici no puixa ne gos parar la botiga ne tenir obrador sens que primerament e ans sia examinat e approbat per los maiorals del dit offici e 


\section{Juan Martínez Vinat. Virgen de la Misericordia, San Jerónimo y San Miguel: el origen del corporativismo sedero en la Valencia bajomedieval (1465-1518)}

haia complida edat de vint anys. E si per los dits majorals serà haut per àbil e sufficient en la dita examinació per a parar botiga, obrador o tint de tanyir seda, aquell aytal sia tengut pagar e pague primerament a la caixa del dit offici cent sous moneda reals de València per rahó del dit examen, e pagats aquells d'aquí avant fet lo dit examen e hagut aquell per sufficient, aquell aytal qui serà stat examinat pare e puixa parar botigua, obrador o tint, e usar com a mestre en lo dit offici. E si sufficient no serà stat atrobat o los dits en lo dit examen, aquell aytal sia reppel lit e no puixa parar botiga, obrador ni tenir tint en algun loch públich o amagat. E si en algun loch públich o amagat aquell aytal obrava de les obres tocants al dit offici, aquell aytal sia incorregut e encorregua en pena de doscents sous. E ultra la dita pena perda la fahena e obra que farà per quiscuna veguada que serà attrobat, applicadors los dits doscents sous e la dita obra lo terç als cófrens del molt alt senyor rey, e lo terç a la caixa del dit offici, e l'altre terç al acusador. E si a aquell aytal qui contrafarà no porà pagar la dita pena sia posat en la presó comuna de la present ciutat, e en aquella estiga pres per temps de trenta dies.

[VI] Ítem, statueixen e ordenen que algun mestre del dit offici no gose ne sia gosat mostrar lo dit offici a moro ne a altre infael. E açò per lo gran dan que de açò se poria seguir a la república e als jóvens christians e obrés qui vinen en lo dit offici, als qualls poria fallir la fahena si la perícia del dit offici venia en mans de infels. E açò sots pena de sexanta sous aplicadors la mitat als cófrens del senyor rey, e l'altre mitat a la caixa del dit offici.

[VII] Ítem més, stauteixen e ordenen que algun obrer del dit offici ne altre que no sia examinat en lo dit offici no puixa tenir seda, filadís ne altre cosa tocant al dit offici en casa de persona alguna que no sia mestre del dit offici e examinat en aquell. E açò per causa dels molts abusos e fraus que 's fan en les obres del dit offici per los tintorés de seda e per les persones qui no tenen intel legència per per fer a de les dites tintes, per la qual rahó les obres del dit offici no 's fan lícites ne tenen aquella perfecció que deven, ne duren tant com deurien, esent-se males e falses són desaseades les obres del dit offici que per mercaderia hixen del regne e ciutat. E axí seran evitats los dits fraus e dans de la república e conservant en les dites coses lo comerç de aquelles. E açò sots pena de xixanta sous applicadors lo terçs als cófrens del dit molt alt senyor rey, l'altre terç a la caixa del dit offici e l'altre terç al acusador.

[VIII] Ítem més, proveheixen, statueixen e ordenen que qualsevol mestre del dit offici de seders e tintorés de seda que farà obres del dit offici o tinyera o tinyir farà, aquelles tals obres haien a fer bones e lícites, ço és, les obres de seda tot de seda, les obres de filadís tot de filadís, les obres de fil tot de fil, a coneguda dels majorals del dit offici. E qui contrafara encorrega en pena de xixanta sous applicadors segons en lo precedent capítol és contengut.

[IX] Ítem més, proveheixen, statueixen e ordenen que algun mestre del dit offici qui serà examinat no gose ne sia gosat de fer les tintes de seda sinó en la forma següent, ço és, los negres de gala e cofoll lícit e sens mixtura alguna, les granes que se hagen a fer per lo semblant bones e lícites, e sobrepeu de sumach e gala, e encara sobrepeu de blanch, los morats de grana que sien fets sobre 


\section{Juan Martínez Vinat. Virgen de la Misericordia, San Jerónimo y San Miguel: el origen del corporativismo sedero en la Valencia bajomedieval (1465-1518)}

grana sens altra mixtura, e lo morat de grana que sia e haia ésser liura per liura, e la grana de seda larga que sia de dos liures per liura, e lo brasill que sia de brasill, los verts e blaus que se hagen de fer de indi lícit e bo, axí de calt com de fret. E que totes les altres colors per lo semblant sien fetes lícites e bones a coneguda dels majorals e vehedors del dit offici. E que axí mateix les listes e miges listes de seda amples e estretes se hagen de fer de bona seda e ben texides, tals de dins com de fora, e totes següents. E que cascuna perça hage tirar trenta sis alnes, e que les vetes sevillanes, axí amples com stretes, se hagen a fer per lo semblant de bona seda, e que quiscuna perça hage tirar de larch texida trenta sis alnes. E axí mateix les vetes reforçades de seda se hagen de fer de bona seda e ben texides següents. E axí que la peça tingua la bondat per entregue en tota la dita peça, e que quiscuna peça de les dites vetes reforçades hage tirar e tira setanta dos alnes de larch com primers se fassan, e hagen a fer de seda, axí la trama com lo ordim. E que cascuna peça dels dits cordons haia tirar e tire texida trenta sis alnes, e que les franges de seda sien e se hagen a fer totes de seda, e que cascuna peça, filadís, axí amples com stretes se facen e se hagen a fer totes peça de aquelles texida tire e hage a tirar trenta sis alnes de larch. E axí mateix les vetes de fil, axí amples com astretes hagen a ésser totes de fil tal de dins com de fora, e ben texides següents, e que cascuna peça tire e hage a tirar trenta sis alnes de larch texides. E que los cordons de filadís, axí grossos com prims, se hagen a fer tot de filadís e que cascuna peça tire e hage tirar de larch trenta sis alnes. E que los cordons de fil, axí amples com prims, se hagen tots de fil, e que cacuna peça tira e hage a tirar de larch trenta sis alnes. $\mathrm{E}$ an axí emperò que si en alguna peça de les dites listes, vetes e cordons fallia dos alnes de tir, segons dessús és dit, poch més o menys, e de la peça de les franges fallia una alna, poch més o menys, que ja per ço les dites no sien perdudes ne per aquelles sien los senyors de aquelles encorreguts en pena alguna, si donchs primerament per lo mustaçaff a consell dels maiorals e veedors del dit offici no era declarat aquelles tals peçes perdudes e no en altra manera. E a per mateix que los parches de seda, axí rasos com de pel, se hagen de fer tots de seda, axí la trama com lo ordim, a coneguda dels dits maiorals e vehedors del dit offici. E qui contrafara encorrega en pena de cent sous aplicadors lo terç al comú de la dita ciutat, e lo terç a la caixa del dit offici, e lo terç al acusador. E ultra la dita pena encara sien perdudes les obres que contra forma de la present ordinació seran fetes, les quals obres axí perdudes sien adquirides la mitat al dit comú de la ciutat, l'altra mitat a la caixa del dit offici.

$[\mathrm{X}]$ Ítem més, proveheixen e ordenen que algú del dit offici no gose ni presumesca pendre moço o moços alguns per apendre lo dit offici per a menys de quatre anys. E açò per quant en lo dit offici recahen moltes coses subtils e ha bé mester lo sobredit temps qualsevol persona que haurà apendre aquell. E que en lo dit temps lo amo sie tengut mostrar bé e diligent lo dit offici als dits moços o servents. E si lo dit moço dins lo dit temps de quatre anys s'en exirà del servir de son amo sens voluntat de aquell e sens justa causa arbitradora e conexedora per los maiorals del dit offici, en tal cas no gos nengú del dit offici pendre ne receptar lo tal moço o fadrí per usar del dit offici. E si lo contrari per algú del dit offici serà fet, cascun d’ells, ço és, lo dit moço e aquell qui 1 pendrà o receptarà e afermarà tal moço encorrega en pena de cent sous per cascuna vegada que contrafet serà, aplicadors la mitat al comú de la ciutat e l'altra mitat a la caixa del dit offici. 


\section{Juan Martínez Vinat. Virgen de la Misericordia, San Jerónimo y San Miguel: el origen del corporativismo sedero en la Valencia bajomedieval (1465-1518)}

[XI] Ítem més, proveheixen e ordenen que per squivar fraus, malícies e debats que ss porien seguir en los affermaments dels moços que volen apendre lo dit offici, sie provehit e manat a qui fon del dit offici que afermara algun moço o fadrí, que aquell tal del dit offici sie tengut notifficar e notiffique als maiorals, que lladonchs seran del dit offici, lo nom del moço que hauran prés e afermat, de quí és fill, hoc encara lo nom del notari qui tal carta haurà rebuda e lo dia que lo dit afermament serà fet, per ço que si volen los dits maiorals fer memòria de tals afermaments en algun libre que $n$ puixen fer, e aquella tal notifficació se hage fer per lo amo e mestre que afermarà lo dit moço dins deu dies continuament comptadors aprés que lo dit afermament serà fet als dit maiorals. E qui contrafarà sie encorregut en pena de cent sous partidors segons dessús és dit en lo precedet capítol, ço és, la mitat al comú de la ciutat e l'altra mitat a la caixa del dit offici.

[XII] Ítem més, proveheixen e ordenen que los maiorals del dit offici que en lo present any seran elets e los que de quí avant se elegiran del dit offici, tota vegada que benvist los serà puixen elegir e fer una e moltes vegades andadors del dit offici, ço és, dos homens, aquells que los maiorals volran e elegiran, remetent-ho a la coneguda de aquells, los quals andadors hagen e sien tenguts a demanar los prohòmens maiorals e altres qualsevol menestrals del dit offici axí per a capítols, ajusts e per altres negocis del dit offici necessaris, als quals andadors sie donat salari competent segons als maiorals e prohòmens del dit offici serà benvist iuxta ses bones consciències. Los quals andadors ab hobediència hagen e sien tenguts servir lo dit offici.

[XIII] Ítem més, proveheixen e ordenen que lo clavari e maiorals del dit offici, dos mesos aprés passat lo any de la llur administració e regiment de son offici, sien tenguts e obligats donar compte e rahó de la llur administració e regimen de son offici als clavari e maiorals qui novament seran elets aprés de aquells, en la qual reddició de comptes sien presents los maiorals vells e novells, ço és, los maiorals que seran exits de la dita maioralia e los maiorals que novament seran elets, ensemps ab los consellers qui seran estats dels dits maiorals, lo qual compte se hage de donar sens requesta alguna, sinó que vengut lo temps de la dita reddició del dit compte, segons dit és, decontinent se done e hage de donar aquell, en la qual reddició de compte los dits clavari e maiorals que aquell tal compte donaran puixen despendre dels béns de la caixa del dit offici cinquanta sous per a dar col lació a les persones que hauran entrevengut en lo dit compte, si als maiorals qui donaran aquells serà benvist que la dita despesa o convit se deia fer.

[XIV] Ítem més, proveheixen e ordenen que cascun any los clavari e maiorals e prohòmens del dit offici puixen tenir quatre capítols ordinaris en los dias que volran e elegiran, e que en quiscun dels dits quatre capítols pague e sie tengut pagar cascú dels del dit offici, axí mestres com obrés, al clavari del dit offici, hun sou en cascun capítol, lo qual se exhegeixca en aquesta manera, ço és, que quiscun dia dels dits quatre capítols ordinaris de quiscun any que 's tendrà capítols, cascun dels dits mestres e obrés, axí hòmens com dones, paguen al clavari del dit offici e a la caixa de aquell hun sou. E que les dites peccúnies que seran procehides dels dits capítols se puixen distribuir per los maiorals del dit offici, axí en necessitat de aquell com en subvenir algunes persones del dit offici 


\section{Juan Martínez Vinat. Virgen de la Misericordia, San Jerónimo y San Miguel: el origen del corporativismo sedero en la Valencia bajomedieval (1465-1518)}

constituhides en necessitat, a coneguda dels dits clavari e maiorals.

[XV] Ítem més, proveheixen, statueixen e ordenen que los dits clavaris e maiorals qui seran del dit offici, a llur bona coneguda, tinguen facultat de remetre o jaquiren, tot o en part, qualsevol pena o penas en que seran encorreguts o encorregue qualsevol del dit offici, remetent-ho a llur bona coneguda.

[XVI] Ítem més, proveheixen e ordonen que qualsevol fill de mestre que volrà per si parar obrador e usar del dit offici hage a ésser primer examinat e obtenir licència dels clavari e maiorals del dit offici para parar obrador, perquè sia vist si aquell serà trobat sufficient, del qual examen aquell tal fill de mestre del dit offici no sia tengut pagar quantitat o cosa alguna. E qui contrafara encorrega en pena de cent sous aplicadors e partidors segons dessús és dit.

[XVII] Item més, proveheixen e ordenen que si algú o alguns del dit offici pendrà o pendran alguna obra a fer o tenir que sia del dit offici, aquell tal fill de mestre del dit offici no sia tengut pagar quantitat alguna. E qui contrafara encorrega en pena de cent sous aplicadors e partidors segons dessús és dit.

[XVIII] Ítem més, proveheixen e ordenen que si algú o alguns del dit offici pendrà o pendran alguna obra a fer o tenyir que sia del dit offici, aquell aytal puix la dita obra haurà començada no puixa deixar aquella ans sia tengut acabarla. E fins haja acabat aquella no puixa pendre fahena alguna de algun altre del dit offici, y açò sots pena de cent sous. En la qual pena encorrega axí lo obrer qui farà la dita fahena com encara lo mestre o obrer del dit offici que aquella tal fahena li donarà, si s mostra o es pot mostrar que aquells tals qui donaran la dita fahena tenia o tenien notícia que aquell tal tenia altra obra començada, la qual pena haja de parti segons dessús en los precedents capítols és contengut, ço és, la mitat al comú de la dita ciutat e la altra mitat a la caixa del dit offici.

[XIX] Ítem més, proveheixen e ordenen que qualsevol home o dona, axí cabalers com altres, puixen texir vetes e listes de seda e fer cordons de seda sens que no hagen mester examen algú, puix emperò la dita seda que texiran sia tenyida per mestre examinat iuxta forma dels precedents capítols. E la dita obra sia bona iuxta forma dels precedents capítols.

[XX] Ítem més, proveheixen e ordenen que los maiorals e offici se puixen ajustar una e moltes e tantes vegades com benvist los serà per rahonar, parlar, tractar, provehir e ordenar qualsevol provisions e ordinacions, capítols e coses necessàries al dit offici útils, spedients e opportunes, de e sobre los fets e negocis del dit offici e entre los qui seran de dit offici, solament a aquells tocant, e que aquells ho puixen fer tota hora que benvist los serà salvant tots temps la fe que deuen al senyor rey. E que açò hagen a fer ab decret e consentiment del portantveus de vovernador de Valencia o de son loctinent, notifficant-ho als magnífichs jurats de la ciutat de València. E si aquells despuix volien mudar, corregir, enadir, millorar, revocar o al primer stament tornar, que ' $\mathrm{n}$ puixen fer ab los consentiments en forma damunt dits. 


\section{Juan Martínez Vinat. Virgen de la Misericordia, San Jerónimo y San Miguel: el origen del corporativismo sedero en la Valencia bajomedieval (1465-1518)}

Testimonis foren presents a les dites coses los honorables en Luys Adzuara, notari, e en Miquel Yvorra, veguer dels magnífichs jurats de la ciutat de València.

Copia preinserta altera talamo scripta et separata in his sep cartis comprehensa presenti abstrabitur a libris annualibus consiliorum et stabilimentorum civitatis Valencie, scribamque aule et magnificorum iuratorum et consilii civitatis eiusdem, et cum eisdem veridici comprobata. Et ut eidem fides indubia, ubique adhibeatur, hic meum solitum artis notari appono signum. Et ut predicta maiori robore firmitate et auctorizate gaude aut finnius vestri pro parte humiler suplicati, ut eadem capitula et omnia et singula preinserta confirmare, de novo concedere, de nostri solita benignitate dignaremur. Nos, vero suplicacionem ipsa benigne intellecta atque admissa, visis dictis et preinsertis capitulis, necnon aorumdem decretacione, confirmacione et concessione per dictos iuratos, racionalem et sindicum factis, quia predicta concernentia commodum et utilitatem dicti offici, ac comorantum in dicta civitate. Tenore presentis, de nostra certa sciencia et expresso, predicta et preinserta capitula et unumquodque ipsorum prout in eis contenta, ac per dictos iuratos, racionalem et sindicum confirmata et concessa fuerunt, laudamus, approbamus, rattificamus et de novo si et quatenus opus est, ad maioris gracie cumulum concedimus, nostreque buiusmodi landacionis, approbacionis, ratifficacionis et confirmacionis, ac nove concessionis munimine et presidio roboramus. Serenissime propterea Ioanne, regine Castelle, Legionis, Granate, etc., filie et primogenite nostre carissime, ac gubernatrici generali, postque felices et longevos dies nostris, in omnibus regnis et terris nostris, Deo propicio, inmediate heredi et legittime successori, intentum aperientes nostrum, sub paterne benediccionis obtentu dicimus, gerentiquoque vices nostri generalis gubernatore et baiulo generali in regno Valencie et signanter, iusticiis, iuratis et aliis offcialibus et subditis nostris in dictis civitate et regno, constitutis et constituendis, dicimus et districte precipiendo mandamus, sub ire et indignacionis nostre incursu, penaque florenorum auri Aragonum mille nostris inferendorum erariis, quatenus nostram buiusmodi laudacionem, approbacionem, ratifficacionem et confirmacionem, ac novam concessionem et omnia et singula de super contenta, ad unguem teneant et inviolabiliter observent et faciant per quos decet observari. Et non contrafaciant vel veniant, aut aliquem contrafacere vel venire sinant racione aliqua sive causa, si dicta serenissima regina, princeps, filia et primogenita nostra carissima, nobis morem gerere, ceteri vero officiales et subditi nostri preter ire et indignacionis nostre incursum preapositam penam cupiunt evitare. In cuius rei testimonium presentem fieri iussimus nostro comuni sigillo inpendenti munita. Datum in civitate Cesaranguste die [en blanco] mensis iulii anno a nativitate Domini millesimo quingentesimo sexto. Regnorumque nostrorum videlicet Sicilie ultra Farum anno tricesimo nono, Aragonum et aliorum vicesimo octavo, Sicilie autem citra Farum et Iherusalem quarto. Yo el rey. 